\title{
Renal Function Analysis of Crane Operators in a Container Terminal and its Related Factors
}

\author{
Muhammad Rizqi Nasution, MD, ${ }^{1}$ Indah S. Widyahening, MD, PhD, ${ }^{2,3}$ Muhammad Ilyas, MD, ${ }^{2}$ \\ Dewi S. Soemarko, MD, $\mathrm{PhD}^{2,4}$ and Aria Kekalih, MD, $\mathrm{PhD}^{2}$ \\ ${ }^{1}$ Occupational Medicine Master Program, Department of Community Medicine, Faculty of Medicine, Universitas Indonesia, Jakarta, Indonesia \\ ${ }^{2}$ Department of Community Medicine, Faculty of Medicine, Universitas Indonesia, Jakarta, Indonesia \\ ${ }^{3}$ Southeast Asian Ministers of Education Organization - Regional Centre for Food and Nutrition (SEAMEO-RECFON) - \\ Pusat Kajian Gizi Regional (PKGR), Universitas Indonesia, Jakarta, Indonesia \\ ${ }^{4}$ Occupational and Environmental Health Research Center, Indonesian Medical Education and Research Institute, \\ Faculty of Medicine, Universitas Indonesia, Jakarta, Indonesia
}

\begin{abstract}
Objective. The objective of this study was to assess factors related to renal function in crane operators at a port container terminal in Indonesia.

Methods. A cross-sectional study on crane operators in Medan Container Terminal, Indonesia, was conducted. Renal function was measured through Glomerular Filtration Rate (GFR). Individual characteristics such as age, nutritional status, fluid consumption, hydration status, and physical activity level were collected. Fluid consumption was obtained from a 24-h food recall questionnaire. Physical activity was measured based on the Bouchard questionnaire. Association was determined by calculating the odds ratio (OR) and its $95 \%$ confidence interval $(\mathrm{Cl})$.
\end{abstract}

Results. A total of 87 subjects were involved. All were male with the median age of $30.1 \pm 2.4$ years old. The prevalence of decreased renal function was $49.4 \%$. Inadequate fluid consumption $(\mathrm{OR}=6.1,95 \% \mathrm{Cl} 2.1-17.7 ; \mathrm{p}<0.001)$ significantly increase the risk of renal function decreased, while being overweight/obese (OR 3.3, $95 \% \mathrm{Cl} 0.7$-11.7; $\mathrm{p}<0.125$ ) and dehydration (OR 2.3, 95\% $\mathrm{Cl} 0.8-26.9 ; \mathrm{p}=0.111$ ) also increase the risk although not significantly.

Conclusion. Inadequate fluid consumption increases the risk of decline in the renal function of crane operators in the container terminal. A company should regularly monitor and evaluate the kidney function of this group of workers through annual medical checkups and provide easier access to drinking water and convenient toilets to improve fluid consumption of the workers.

Key Words: renal function, fluid consumption, dehydration, crane operator

\section{INTRODUCTION}

Corresponding author: Indah S. Widyahening, MD, PhD Department of Community Medicine

Faculty of Medicine

Universitas Indonesia

Jakarta 10430, Indonesia

Email: Indah_widyahening@ui.ac.id
Impaired renal function is associated with an increased risk of several complications, such as anemia and bone mineral metabolism disorders, cardiovascular events, and chronic renal failure, which will require renal transplant in the end. ${ }^{1}$ Early detection of renal disorders is critical to prevent and delay the progression of the disease and reduce further complications. ${ }^{1,2}$ Renal disease has been recognized as an increasing global health problem. Treatment for the renal disease was the second-largest financial expenditure of the national health insurance after heart disease in Indonesia. ${ }^{3}$ Chronic renal diseases initially show no signs and symptoms, but they can progress to renal failure. Renal diseases can be prevented and treated, and the possibility of getting effective therapy will be greater if known earlier. ${ }^{4}$ 
One of the factors causing impaired kidney function is dehydration, and crane operators are a group of workers who are at risk of experiencing dehydration due to the environmental condition at work. A health examination of crane operators working in a container terminal in North Sumatera, Indonesia, in 2018 found that more than 30\% of workers had a decrease in renal function. This result is alarming and warrants some interventions to prevent further impairment of renal function of the workers. The present study aimed to know the factors that affect renal function among crane operator workers at the container terminal.

\section{METHODS}

A cross-sectional study was conducted among crane operators in a container terminal in Medan, North Sumatera, Indonesia. Each subject that meets the selection criteria signed informed consent. The Research Ethics Committee of the Faculty of Medicine Universitas Indonesia - Cipto Mangunkusumo Hospital approved the study (No. 20-050565). The inclusion criteria were male of productive age who work as crane operator in the container terminal. Those identified as having fever, consuming diuretic drugs, having a history of hypertension or diabetes mellitus, or kidney disease were excluded.

Primary data involved measurement of height and weight, fluid consumption, and physical activity. Secondary data was taken from medical records, including age, blood creatinine level, and urine gravity. The dependent variable was renal function. The evaluation of renal function was based on the Glomerular Filtration Rate (GFR) assessment through blood creatinine levels and converted using the CKD EPI formula. ${ }^{5,6}$ The GFR was classified into two categories, namely normal (GFR $>0 \mathrm{~mL} /$ minute) and decreased $(<90$ $\mathrm{mL} /$ minute). Blood creatinine levels were obtained from the medical records of the worker health examination in 2019. Age was categorized into $<40$ years old and $\geq 40$ years old. ${ }^{7}$ Nutritional status was determined through body mass index (BMI) based on the Asia Pacific BMI category, which was categorized as underweight $\left(B M I<18.5 \mathrm{~kg} / \mathrm{m}^{2}\right)$, normoweight (BMI 18.5-22.9 kg/m²), overweight (BMI 23-24.9 kg/m $\mathrm{m}^{2}$ ) and obese $\left(B M I \geq 25 \mathrm{~kg} / \mathrm{m}^{2}\right) .{ }^{8}$ Hydration status was quantified by measuring urine specific gravity (USG). USG had been taken by urine solute mass as well as concentration. This present study used the threshold of any USG value $\geq 1.020$ to define dehydration. ${ }^{9}$ The data of USG was based on the urinalysis data from the medical records.

To calculate fluid consumption, this present study used a 24-h food recall questionnaire. A medical doctor conducted the recall interview. Total fluid consumption was considered to be the sum of all types of drink. All of the analyses were performed, taking into account the $\mathrm{mL}$ of water content. Fluid consumption categories were based on the Indonesian Occupational Doctors Association (PERDOKI) 2015 recommendation for fluid consumption among workers. The recommendation stated that workers with moderate work activities require 150-200 cc of fluid consumption per hour or a minimum of $2400 \mathrm{~mL}$ per day. The categories were defined as adequate (water consumption of $\geq 2400 \mathrm{~mL}$ ) and inadequate (consumption of $<2400 \mathrm{~mL}$ of water). ${ }^{10}$

Bouchard questionnaire was used to assess daily living physical activity. In the Bouchard Questionnaire, all types of information related to when the activity starts and stops, intensity rating, and mode/type of activity were recorded. The scale of the activities is added up and multiplied by the determined metabolic equivalent of task (MET) value. ${ }^{11,12}$ We also measured the environment temperature at work by measuring the Wet Bulb Globe Temperature (WBGT) outside the cabin to assess the fluid requirement based on the local temperature.

All data were analyzed using SPSS version 22.0. Chisquare test and the calculation of odds ratio and its $95 \%$ Confidence Interval (CI) was used to analyze the significance of the relationship between independent variables (Age, physical activity, BMI, fluid consumption, hydration status) and renal function. Data reported as total number of each group (n) with statistical significance set a priori at $\mathrm{p}<0.05$.

\section{RESULTS}

The total number of crane operators was 120 men, with 87 participating in the study. The characteristics of the study subjects are presented in Table 1 .

The majority of the workers were those aged $<40$ years, the youngest being 23 and the oldest was 43 years. Fluid consumption was ranged from 1350 to $3350 \mathrm{~mL}$ of fluid per day, with $64.4 \%$ of the study subjects having inadequate fluid consumption. The examination of the hydration status found that $44.9 \%$ of workers were dehydrated. Obesity was found among $47.3 \%$ of workers. The level of physical activity of the crane operator was in the medium activity category, which was around 4-6 METs during work. This study found that the prevalence of decreased renal function was $49.4 \%$. Renal function values were range from 48.7 to 173.9 $\mathrm{mL} /$ minute. The environment temperature at work showed a median temperature of 32.4 (range 28-34.5) ${ }^{\circ}$ Celcius.

Table 2 shows the relationship between renal function with age, physical activity, fluid consumption, BMI, and hydration status. A bivariate analysis using chi-square found that fluid consumption and hydration status significantly correlate with renal function, while BMI has a moderate relationship. A multivariate analysis using a logistic regression test found that inadequate fluid consumption significantly increased the risk of decreased renal function with an odds ratio of 6.1 (95\% CI 2.13-17.7). However, no significant associations between a decreased renal function with BMI and hydration status were found during the multivariate analysis. 
Table 1. Characteristics of crane operator container terminal in Medan, Indonesia ( $\mathrm{n}=87$ subjects)

\begin{tabular}{|c|c|c|}
\hline Characteristics & $\begin{array}{c}\text { mean } \pm \mathrm{SD} / \text { median } \\
(\min -\max )\end{array}$ & n (\%) \\
\hline Age (Years) & $30.1 \pm 2.4$ & \\
\hline$<40$ years & & $85(97.7)$ \\
\hline$\geq 40$ years & & $2(2.3)$ \\
\hline Working Period (Years) & $8.3 \pm 1.6$ & \\
\hline$<8$ years & & $45(51.7)$ \\
\hline$\geq 8$ years & & $42(48.3)$ \\
\hline Physical activity (METs) & $4.17 \pm 0.67$ & \\
\hline Moderate & & 85 (97.7) \\
\hline Heavy & & $2(2.3)$ \\
\hline Glomerulus Filtration Rate (mL/min) & $87.71 \pm 20.9$ & \\
\hline Normal & & $44(50.6)$ \\
\hline Decreased & & $43(49.4)$ \\
\hline Fluid Consumption (mL/day) & $2100(1350-3350)$ & \\
\hline Adequate (>2400 mL) & & $32(35.6)$ \\
\hline Inadequate $(<2400 \mathrm{~mL})$ & & $56(64.4)$ \\
\hline \multicolumn{3}{|l|}{ Hydration Status } \\
\hline Euhydration (USG $\geq 1,020$ ) & & $48(55.1)$ \\
\hline Dehydration (USG < 1, 020) & & $39(44.9)$ \\
\hline \multicolumn{3}{|l|}{ Nutrition status } \\
\hline Normoweight $\left(\mathrm{BMI}<23 \mathrm{~kg} / \mathrm{m}^{2}\right)$ & & $28(32.1)$ \\
\hline Overweight (BMI 23-25 kg/m²) & & $18(20.6)$ \\
\hline Obesity (BMl>25 kg/m²) & & $41(47.3)$ \\
\hline
\end{tabular}

\section{DISCUSSION}

The prevalence of renal function decline in crane operators at the container terminal is $49.4 \%$. Inadequate fluid consumption significantly increased the risk of the decrease in crane operators by six times. Higher BMI and dehydration also increased the risk, although not statistically significant. We found no association between individual factors such as age and physical activity, with renal function in this study.

This study found that the amount of fluid consumption of workers is at least $1350 \mathrm{~mL}$ per day with a maximum amount of liquid as much as $3350 \mathrm{~mL}$. Drinking behavior among crane operator operators in our study was poor, especially during working time. Interview with subjects found that more than $50 \%$ of workers did not have good drinking habits in working time. Most workers didn't want to drink while working because they must work in their crane cabin in a very high tower, making it difficult to go to the restroom. Even though the company allows workers to bring drinks while in the cabin and the company provides one drinking water refill in the break room. In addition, they also prefer to stay in the cabin during break time.

Although a study by Suzuki reported that the level of physical activity influences renal function, we found no such relationship in our study. ${ }^{12}$ This might be due to the homogeneity of the physical activity level in our research. The physical activities of most of the workers in this study were of moderate activity or 3-6 METs, and only two workers were categorized as having a high level of physical activity ( $>6$ METs). The job as a crane operator is mostly sitting in their crane cabin while operating it. They could go to the cabin using stairs or an elevator, but some of the elevators do not function optimally. They don't do much physical activity outside of work. Yet the two workers categorized as having a high level of physical activity conducted strenuous exercise diligently, such as playing soccer and cycling both on weekdays and holidays. Age was not related to a decrease in renal function in this study because the age group of our subjects was similar.

Table 2. Relationship between renal function with age, physical activity, fluid consumption, BMI, and hydration status

\begin{tabular}{|c|c|c|c|c|c|c|}
\hline \multirow{2}{*}{ Variable } & \multicolumn{2}{|c|}{ Renal Function } & \multicolumn{2}{|c|}{ Bivariate analysis } & \multicolumn{2}{|c|}{ Multivariate Analysis } \\
\hline & Normal & Decline & OR $(95 \% \mathrm{Cl})$ & $\mathbf{p}^{*}$ & aOR $(95 \% \mathrm{Cl})$ & $\mathbf{p}^{* *}$ \\
\hline \multicolumn{7}{|l|}{ Age (Years) } \\
\hline$<40$ years & $47(55.2)$ & $38(44.8 \%)$ & & & & \\
\hline$\geq 40$ years & $1(50)$ & $1(50.0 \%)$ & $1.02(0.9-1.1)$ & 0.46 & & \\
\hline \multicolumn{7}{|l|}{ Physical activity (METs) } \\
\hline Moderate & $43(50.6)$ & $42(49.4 \%)$ & $0.99(0.9-1.1)$ & & & \\
\hline Heavy & $1(50)$ & $1(50.0 \%)$ & & 0.74 & & \\
\hline \multicolumn{7}{|l|}{ Fluid Consumption (mL/day) } \\
\hline Adequate (>2400 mL) & $20(76.9 \%)$ & $6(23.1 \%)$ & & & & \\
\hline Inadequate $(<2400 \mathrm{~mL})$ & $24(39.3 \%)$ & $37(60.7 \%)$ & $6.2(2.3-16.8)$ & $<0.001$ & $6.1(2.1-17.7)$ & 0.001 \\
\hline \multicolumn{7}{|l|}{ Nutrition status } \\
\hline Normoweight (BMI < 23 kg/m²) & $17(60.7 \%)$ & $11(39.3 \%)$ & & & & \\
\hline Overweight - Obese $\left(\mathrm{BMI} \geq 23 \mathrm{~kg} / \mathrm{m}^{2}\right)$ & $27(45.8 \%)$ & $32(54.2 \%)$ & $0.82(0.6-1.1)$ & 0.193 & $3.3(0.7-11.7)$ & 0.125 \\
\hline \multicolumn{7}{|l|}{ Hydration Status } \\
\hline Euhydration & 34 (70.8\%) & $14(29.2 \%)$ & & & & \\
\hline Dehydration & $10(25.6 \%)$ & 29 (74.4\%) & $7.0(2.7-18.2)$ & $<0.001$ & $2.3(0.8-26.9)$ & 0.111 \\
\hline
\end{tabular}

${ }^{*}$ Chi-Square test; ${ }^{* *}$ Logistic Regression 
Half of the crane operators in this study have a decreased renal function, and seven subjects had a moderate category in decreased renal function. A study reported that the prevalence of renal disorders in plantation workers in Central America and southern Mexico was nine times higher than the age-matched population in the United States. ${ }^{13}$ Most renal diseases attack the nephron, resulting in loss of its ability to filter. Damage to the nephron can occur quickly and often as a result of intoxication or trauma. But most renal diseases slowly and quietly destroy nephrons. Damage only appears after a few years or even decades. Most renal diseases attack both kidneys at once. ${ }^{14}$ End-Stage Renal Disease (ESRD) occurs when renal function is very poor, and sufferers experience metabolic disorders of protein, fat, and carbohydrates. The reduced renal function causes the breakdown of toxic proteins, namely urea and nitrogen.

Crane operators with inadequate fluid consumption have a 6.1 times higher risk for decreased renal function. In addition, the hydration status factor also affects renal function, although not statistically significant. Subjects with dehydration have 2.3 times more risk of decreased renal function compared with dehydration. The measurement of fluid consumption, which was not conducted simultaneously with the kidney function examination, might be related to the insignificant result due to measurement bias. Further, higher BMI appeared also to increase the risk of renal function decreased. A study among healthy adults in Spain reported that fluid consumption was inversely correlated with BMI. ${ }^{15}$

We found that $45 \%$ of workers in this study were in dehydration status, which might be due to the combination of poor drinking behavior and environmental heat. Previous studies stated that low fluid consumption seems to correlate with increased comorbidity and decreased renal function. Adequate total fluid consumption does not have a significant relationship with cardiovascular disease but has a significant relationship with positive results in reducing the incidence of chronic renal disease. ${ }^{13,14}$ In addition to population-based cohort studies, the risk of CKD and annual decrease in eGFR are inversely correlated with 24-hour fluid consumption and urine volume. ${ }^{14}$ Increased fluid consumption increases the ability of the kidneys to excrete sodium, whereas the antidiuretic action of vasopressin results in substantial sodium retention. Repeated dehydration and volume depletion can also cause $\mathrm{CKD}$ through other mechanisms; namely, volume reduction can cause hypokalemia, which causes intrarenal vasoconstriction and hypoxia so that the chronic impact of this event is tubulointerstitial injury. However, the tubular vacuole is common in hypokalemia nephropathy. ${ }^{13,14}$

A study among this group of workers is currently minimal, although, in this current industrial era, the number of workers in this occupation is steadily increasing. Manuals on crane operators' health and safety only mention ergonomic factors and occupational accidents as the health hazards in this occupation. ${ }^{16,17}$ However, this study also has limitations due to its cross-sectional design, which is not the most robust design to establish causation. Specific environmental conditions in this study conducted in the tropical climate also might influence the higher number of subjects with dehydration status. Yet, the result of this study should warrant the industries which involved crane operators about the additional health risk and how to prevent it.

\section{CONCLUSION}

Inadequate fluid consumption increased the risk of decline in renal function among crane operators in the container terminal. Company should regularly monitor and evaluate the kidney function of this group of workers through annual medical checkups and provide easier access to drinking water and convenient toilets to improve fluid consumption of the workers.

\section{Statement of Authorship}

All authors participated in the data collection and analysis, agreed to be accountable for all aspects of the work, and approved the final version submitted.

\section{Author Disclosure}

The authors declared that they have no conflicts of interest.

\section{Funding Source}

No funding support.

\section{REFERENCES}

1. Toussaint N. Screening for Early Chronic Kidney Disease. The CARI Guidelines. Australia: Saunder; 2012. pp. 30-55.

2. Weanen. New Marker for Kidney Disease. Clinical Chemistry, 3rd ed. USA: Elsevier; 2002. pp. 1375-89.

3. Ministry of Health of the Republic of Indonesia. Chronic Kidney Diseases Situation. Jakarta: Data and Information Center; 2017. pp. 1-10.

4. Hill NR, Fatoba ST, Oke JL, Hirst JA, O'Callaghan CA, Lasserson DS, et al. Global Prevalence of Chronic Renal Disease - A Systematic Review and Meta-Analysis. PLOS-One. 2016; 11(7):1-15

5. Frank C. Biomarkers of Impaired Renal Function. Wolters Kluwer Health. 2010: 525-37.

6. Lesley A, Josef CJ, Greene T, Levey AS. Assessing Renal Function Measured and Estimated Glomerular Filtration Rate. N Engl J Med. 2006; 354:2473-83.

7. Denic A, Richard J, Rule AD. Structural and Functional Changes with the Aging Kidney. Adv Chronic Kidney Dis. 2016; 23(1): 19-28.

8. Pan WH, Yeh WT. How to Define Obesity? Evidence-based Multiple Action Points for Public Awareness, Screening, and Treatment: an Extension of Asian-Pacific Recommendations. Asia Pac J Clin Nutr. 2008; 17(3): 370-4.

9. Hew-Butler TD, Eskin C, Bickham J, Rusnak M, VanderMeulen M. Dehydration is How You Define It: Comparison of 318 Blood and Urine Athlete Spot Checks. BMJ Open Sport Exerc Med. 2018; 4(1): $1-7$.

10. Soemarko DS. Guidelines on the Fluid Intake of Workers to be Healthy and Productive Jakarta: Ministry of Health of the Republic of Indonesia; 2015.

11. Sylvia LG, Bernstein BS, Hubbard JL. A Practical Guide to Measuring Physical Activity. J Acad Nutr Diet. 2014; 114(2): 199-208. 
12. Suzuki M. Physical Exercise and Renal Function. J Phys Fitness Sports Med. 2015; 4(1): 17-29.

13. Nerbass FB, Filho RP, Clark WF, Sontrop JM, McIntyre CW, Moist L. Occupational Heat Stress and Renal Health: From Farms to Factories. Kidney Int Rep. 2017; 2(6): 998-1008.

14. Levey AS, Coresh J, Greene T, Marsh J, Stevens LA, Kusek JW, et al. Expressing the Modification of Diet in Renal Disease Study Equation for Estimating Glomerular Filtration Rate with Standardized Serum Creatinine Values. Clin Chem. 2007; 53(4): 766-72.

15. Laja García AI, Moráis-Moreno C, Samaniego-Vaesken M, Puga AM, Partearroyo T, Varela-Moreiras G. Influence of Water Intake and Balance on Body Composition in Healthy Young Adults from Spain. Nutrients. 2019; 11:1923. doi: 10.3390/nu11081923
16. International Labor Organization. International Hazard Datasheets on Occupation: Crane Operator (Construction work). International Labor Organization [Internet]. 2000 [cited 2021 January 14]. Available from: https://www.ilo.org/wcmsp5/groups/public/---ed_protect/--protrav/---safework/documents/publication/wcms_192399.pdf

17. Port Equipment Manufacturers Association. Crane Operator Health and Safety. Port Technology [Internet]. 2018 [cited 2021 January 14]; 78. Available from: https://www.porttechnology.org/technicalpapers/crane_operator_health_safety/

The Acta Medica Philippina is now accepting original scientific papers, review articles and case reports for its upcoming issues. Please follow the format for submission as indicated in the "Instructions to Authors" elsewhere in the journal. All papers received shall be properly acknowledged. For inquiries and submission of proposals, please email us at actamedicaphilippina.upm@up.edu.ph 